The Determinants of Total IT Outsourcing:

An Empirical Investigation of French and German Firms

\author{
Jérôme Barthélemy * \\ ESSEC Business School \\ Avenue Bernard Hirsch \\ 95021 Cergy Pontoise Cedex - FRANCE \\ Tel.: +33.1.34.43.31.98 \\ e-mail: barthelemy@essec.fr
}

\author{
Dominique Geyer \\ AUDENCIA Nantes \\ 8 , route de la Joneliere \\ 44312 Nantes Cedex 3 - FRANCE \\ Tel.: +33.2.40.37.34.74 \\ e-mail: dgeyer@audencia.com
}




\title{
The Determinants of Total IT Outsourcing: An Empirical Investigation of French and German Firms
}

\begin{abstract}
An increasingly large number of firms outsource their Information Technology (IT) to outside vendors. Firms that contemplate IT outsourcing have two alternatives: (1) outsource part of their IT activity (i.e., "selective outsourcing") or (2) outsource their entire IT activity (i.e., "total outsourcing"). It has been repeatedly reported that total IT outsourcing efforts have far lower success rates than selective ones. Using primary data collected both in France and Germany, we investigate the reasons why some firms engage in this apparently sub-optimal practice.
\end{abstract}

Key words

MIS management, Outsourcing, France, Germany

\section{INTRODUCTION}

Information Technology (IT) outsourcing can be defined as "the significant contribution by external vendors in the physical and/or human resources associated with the entire or specific component of the IT infrastructure in the user organization" (26). IT outsourcing is not a new phenomenon. Time sharing, which involves purchasing computer time, was very popular in the 1960s and 1970s. From the mid-1980s on however, a new type of IT outsourcing started blossoming. There are at least three major differences between new and more traditional types of IT outsourcing (15). First, outsourcing is no longer restricted to small and medium-sized companies that do not possess their own IT infrastructure. Second, companies outsource an increasingly large range and depth of services. Third, personnel and equipment are frequently transferred to the vendor. Though the new type of IT outsourcing started developing in the mid-1980s, it really took off after the very much-heralded contract 
between Kodak and IBM in 1989. This landmark deal legitimized the practice of IT outsourcing among U.S. Fortune 500 firms (25).

Firms that contemplate IT outsourcing have two basic alternatives. Either they can outsource only part of their IT activity. Lacity, Willcocks and Feeny (20 and 21) have coined the expression "selective outsourcing" to describe this practice. Or they can outsource their entire IT activity, a practice usually referred to as "total outsourcing". There is anecdotal and more rigorous evidence that selective IT outsourcing has higher success rates than total IT outsourcing (19, 20 and 21). However, total IT outsourcing is not an uncommon practice. For instance, one study reported that $20 \%$ of IT outsourcing efforts could be described as total IT outsourcing (19). The aim of this paper is to understand why some firms engage in an apparently sub-optimal practice such as total IT outsourcing. Despite the large body of literature on IT outsourcing, the determinants of the "total vs. selective" IT outsourcing decision have not been examined by any published study of which we are aware.

The paper is organized as follows. In the second section, we review the IT outsourcing literature and more precisely define the concepts of total and selective IT outsourcing. In the third section, research hypotheses are presented. In the fourth section, we describe the data - a sample of French and German large firms - and the methodology. In the fifth section, we present the findings. The implications of the findings are discussed in the sixth section and the last section concludes.

\section{RESEARCH BACKGROUND}

\subsection{IT Outsourcing Literature}

Outsourcing has received a lot of attention from the IT literature. The extant literature focuses on two key topics. The first stream of research investigates the determinants of the IT outsourcing decision. In a landmark piece of research, Loh and Venkatraman (26) empirically 
showed that the degree of IT outsourcing was positively related to both business and IT costs. They also established that the degree of IT outsourcing was negatively related to IT performance. This finding was confirmed by Teng, Cheon and Grover (39) who showed that the gap between the actual and desired level of IT performance was a major determinant of IT outsourcing. The interactions between economic and institutional factors were also investigated. Empirical evidence shows that a bank's conformity to institutional pressures essentially depends on the type of institutional influence (i.e., peer influence vs. legal sanctions from federal regulators) and the relative power of the bank (2). More recently, research based on the technology acceptance model revealed that perceived usefulness and ease of use mediate the impact of economic factors on outsourcing decisions (9).

The second stream of research focuses on IT outsourcing vendor management. The main finding is that partnership quality is a key determinant of IT outsourcing success (23 and 24). The antecedents of partnership were also investigated (23). While partnership quality was positively impacted by participation, communication, information sharing and top management support, it was negatively impacted by the age of the relationship and mutual dependency. Recent findings suggest that IT outsourcing success is simultaneously influenced by relational exchange factors (i.e., partnership, flexibility, monitoring and role integrity) and also Transaction Costs Economics factors (i.e., asset specificity) (37).

\subsection{Total and selective IT Outsourcing}

The total vs. selective IT outsourcing dichotomy is classic in the literature. Lacity and Willcocks (19) defined total outsourcing as "the decision to transfer the equivalent of more than $80 \%$ of the IT budget for IT assets, leases, staff, and management responsibility to an external IT provider" and selective outsourcing as "the decision to source selected IT functions from external provider(s) while still providing between $20 \%$ and $80 \%$ of the IT 
budget internally." They empirically found that selective IT outsourcing decisions were more successful (measured as the achievement of expected cost savings) than total IT outsourcing. More specifically, $85 \%$ of selective outsourcing and $29 \%$ of total outsourcing decisions met customers' expected cost savings.

The superiority of selective outsourcing over total outsourcing can be attributed to the fact that IT is a highly heterogeneous function. The IT function consists of commodities such as data centers (i.e., a highly structured activity that was one of the first to be outsourced), telecommunications networks and micro-computers (i.e., two activities that reflect the trend toward standardization and standard configurations in IT) and specific activities such as applications development, system design and systems integration (39). Though IT vendors benefit from economies of scale by pooling capacity across different customers, specific IT activities should not be outsourced. Indeed, vendors may standardize them to the extent that the unique needs of the client are no longer met (2). Outsourcing specific IT activities is also dangerous because it creates a dependence situation that may be exploited by the vendor (44). In sum and as Lacity, Willcocks and Feeny (21) put it: "Selective outsourcing meets customers' needs while minimizing the risks associated with total outsourcing approaches". Thus, an important research question is to understand why some firms engage in a practice that seems as sub-optimal as total IT outsourcing.

\section{RESEARCH HYPOTHESES}

\section{Cost motivation}

Few empirical studies have tested the link between IT costs and outsourcing. Empirical results are also mixed. Some authors have found that high IT costs lead to outsourcing (26). On the other hand, it was not found that a cost gap (i.e., difference between actual and desired IT costs) leads to outsourcing (39). The inconsistency between these two results may be 
attributed to the fact that the first study focused on actual IT costs while the second one focused on the perceived gap between internal and external IT costs.

While all types of IT outsourcing may present cost savings opportunity, some of them are typically associated with total IT outsourcing. Firstly, an immediate benefit of total IT outsourcing is a cash infusion through the sales of IT assets to the vendor (10). As a rule, transferring the entire IT department to an outside vendor entails a larger cash infusion than transferring only part of it. Secondly, dealing with a single vendor - as is often the case with total IT outsourcing - entails lower vendor management costs. This can be explained through the fixed nature of the costs of negotiating and monitoring IT contracts $(7,13)$. Thirdly, total IT outsourcing may lead to larger economies of scale than selective IT outsourcing because of the sheer size of the contract. Though total IT outsourcing is a riskier practice than selective IT outsourcing, it may be an attractive opportunity for firms that desperately and quickly need to cut IT costs.

Hypothesis 1: For firms that outsource IT, the likelihood of total outsourcing is higher when the cost reduction motivation is strong.

\section{Performance motivation}

Some firms lack IT skills. Thus, the external acquisition of complementary resources and capabilities may be necessary. This reasoning is based on the Resource-Based View of the firm $(1,6,14,38)$. Empirical support was found for the proposition that the extent of IT outsourcing is determined by the gap between the desired and actual level of IT performance (39). It was also found that low returns on IT investment lead firms to outsource a larger share of their IT budget (26). However, none of these studies distinguished between selective and total IT outsourcing. 
The implications of the positive relationship between low IT performance and outsourcing are not straightforward for the total vs. selective outsourcing dilemma. We propose that a strong performance improvement motivation should reduce the likelihood of total IT outsourcing. As suggested above, total IT outsourcing often entails dealing with a single vendor. No single IT vendor can be proficient for every IT activity $(12,19)$. Hence, firms should be reluctant to transfer their entire IT activity to a single vendor when performance is an important issue. We expect them to carefully select a specialized vendor for each component of IT, as this "best-of-breed" approach should improve IT performance more than total IT outsourcing.

Hypothesis 2: For firms that outsource IT, the likelihood of total outsourcing is lower when the performance improvement motivation is strong.

\section{IT Department Size}

It has been repeatedly reported that large organizations are more likely to adopt innovations (35 and 45). While a direct implication is that the likelihood of outsourcing should be correlated with IT department size, the impact of IT department size on the actual type of outsourcing (i.e., total vs. selective outsourcing) has remained unexplored. IT outsourcing decisions may be viewed as either efficiency or politically driven (18). Both the efficiency and political perspectives suggest that large IT departments are less likely to be totally outsourced than smaller ones.

The driving force behind the efficiency perspective is that outsourcing decreases IT costs and improves IT performance. Regarding costs, large internal IT departments enjoy internal economies of scale due to their sheer size. When an IT department has reached a critical mass, internal economies of scale may be as large as those enjoyed by specialized vendors (8). 
Regarding performance, large IT departments are less likely to lack expertise than small IT departments facing resource shortages.

The driving force behind the political perspective is that large IT departments have more resources than smaller ones. Consequently, it will be easier for them to resist pressures from the top management and other departments of the company (13). In sum, we expect large IT departments to be able to justify internal operations and more easily resist being totally dismantled as is the case with total IT outsourcing (18).

Hypothesis 3: For firms that outsource IT, the likelihood of total outsourcing is lower when the IT department is large.

\section{Decision-making}

The IT literature generally distinguishes between centralized and decentralized environments. At one extreme of the continuum (i.e., centralized environment), IT resources are managed by a centralized IT department. At the other extreme of the continuum (i.e., decentralized environment), IT resources are managed by users dispersed throughout the firm $(16,36)$. In the case of IT outsourcing decision-making however, there are three basic possibilities. Firstly, the decision may be made by the Chief Information Officer (CIO). Secondly, the decision may be made by a non-IT senior executive such as the Chief Executive Officer (CEO) or the chief Financial Officer (CFO). Thirdly, both the CIO and a non-IT senior executive may make the decision. Lacity and Willcocks (19) have studied the impact of the decision-maker(s) on IT outsourcing success. They found that joint decisions (i.e., CIO and non-IT senior executives) had higher success rates because of the mix of political power and technical skills required by IT outsourcing.

Regarding the impact of the decision-maker(s) on the type of IT outsourcing, we propose that total IT outsourcing decisions are more likely to be made when non-IT senior executives 
are involved in the process. For some non-IT executives, the IT department is a "black box" or a "money sink" (41). Such executives may view total outsourcing as a way to get rid of IT. On the other hand, IT executives are likely to resist total IT outsourcing decisions. Indeed, such a decision would send a clear signal that IT does not belong to the "core business" (5). Hypothesis 4: For firms that outsource IT, the likelihood of total outsourcing is higher when non-IT senior executives are involved in the decision process.

\section{Impact of sector IT intensity}

IT intensity varies greatly from one sector to another. Sectors such as banking, financial services, insurance and high tech are generally described as highly IT intensive (32). We contend that total IT outsourcing should be less frequent in IT intensive sectors for the following reasons.

On the one hand, total outsourcing often entails relinquishing control over the entire IT activity. As this may threaten their competitive advantage, firms from IT intensive sectors should be reluctant to outsource their entire IT activity. On the other hand, selective IT outsourcing is a powerful way to acquire resources that are not internally available by using a "best-of-breed" approach (19). Hence, even firms from IT intensive sectors may resort to selective outsourcing to fill resource gaps and improve their overall IT expertise level (39). Hypothesis 5: For firms that outsource IT, the likelihood of total outsourcing is lower in ITintensive sectors.

\section{Impact of Institutional Environment}

North (28 and 29) defined institutions as the constraints - both formal and informal - that shape human interactions. Formal constraints refer to political rules, economic rules and contracts while informal constraints refer to the norms and value system of a society. 
Consistent with North (28 and 29), we propose to test the hypothesis that institutional differences have an impact on the choice between selective and total IT outsourcing.

According to Lawrence (22), German managers are less open to external influences than managers from other countries. They are characterized by "organizational shamelessness", which is the unwillingness to conform to conventional wisdom on business practices just for the sake of doing so. Contrary to classic types of outsourcing such as time sharing, total IT outsourcing is frequently associated with the United States (25). Because of "organizational shamelessness", we expect German managers to be more reluctant than French ones to conform to what they may consider as a mere fad. In other words, German managers should be more reluctant than French managers to outsource their entire IT department.

Hypothesis 6: For firms that outsource IT, the likelihood of total outsourcing is higher for French firms than for German firms.

\section{RESEARCH METHOD}

\subsection{Sample}

To test our hypotheses, we sent a questionnaire to the largest 500 French firms and the largest 500 German firms. By using a broad population, we sought to enhance the external validity of the study. 160 questionnaires were filled out by senior IT managers and returned. The overall response rate of $16 \%$ (i.e. $12.2 \%$ of the French sample and $19.8 \%$ of the German sample) is low for two reasons. First, obtaining survey responses from executives is always problematic. Second, financial constraints prevented us from sending reminders to nonrespondents. However, our response rate is consistent with recently published IT outsourcing studies such as (31).

The breakdown of the sample by country and by industry is summarized in Table 1 . Overall, the structure of the French and German samples was very similar. 
Table 1: Distribution of surveyed firms across sectors $(N=160)$

\begin{tabular}{lcccccc}
\hline \multicolumn{1}{c}{ Sector } & \multicolumn{2}{c}{ French sample } & \multicolumn{2}{c}{ German sample } & \multicolumn{2}{c}{ Both samples } \\
\hline Energy and extraction & 5 & $\mathbf{8 \%}$ & 13 & $\mathbf{1 3 \%}$ & 18 & $\mathbf{1 1 \%}$ \\
Raw materials and chemicals & 9 & $\mathbf{1 6 \%}$ & 14 & $\mathbf{1 4 \%}$ & 23 & $\mathbf{1 5 \%}$ \\
Manufacturing industry & 13 & $\mathbf{2 1 \%}$ & 17 & $\mathbf{1 7 \%}$ & 30 & $\mathbf{1 9 \%}$ \\
Trade/Food/Catering & 14 & $\mathbf{2 3 \%}$ & 21 & $\mathbf{2 2 \%}$ & 35 & $\mathbf{2 2 \%}$ \\
Banking/Finance/Insurance & 15 & $\mathbf{2 4 \%}$ & 24 & $\mathbf{2 5 \%}$ & 39 & $\mathbf{2 4 \%}$ \\
Others & 5 & $\mathbf{8 \%}$ & 10 & $\mathbf{1 0 \%}$ & 15 & $\mathbf{9 \%}$ \\
Total number of firms & 61 & $\mathbf{1 0 0 \%}$ & 99 & $\mathbf{1 0 0 \%}$ & 160 & $\mathbf{1 0 0 \%}$ \\
\hline
\end{tabular}

The goal of this study was to investigate the determinants of total vs. selective IT outsourcing. Since the firms that responded to our questionnaire did not necessarily outsource all or part of their IT, we could only use the questionnaires returned by the seventy-two firms that had outsourced all or part of their IT (i.e., $45 \%$ of the respondents). Though the sample size is small, it is similar to that of recently published IT outsourcing studies (e.g., 24).

\subsection{Variables}

We used the following variables to test our model. The dependent variable - total IT outsourcing - was a dummy variable coded "1" when a firm outsourced its entire IT department and " 0 " otherwise. To measure the cost motivation, we asked key informants to assess the extent to which the aim of IT outsourcing was to: (1) cut IT costs, (2) improve IT cost awareness and (3) improve control over IT costs. All three variables were measured using a five-point Likert scale $(1=$ strongly disagree, $5=$ strongly agree $)($ Cronbach Alpha $=0.65)$. To assess the performance motivation, we asked key informants to assess the extent to which the aim of IT outsourcing was to: (1) provide access to outside specialists; (2) provide access to outside technological knowledge; (3) enable the firm to move to a new IT architecture. All three variables were measured using a five-point Likert scale $(1=$ strongly disagree, $5=$ 
strongly agree) $($ Cronbach Alpha $=0.65)$. IT department size was measured on a five-pointLikert scale ("less than 20 people", "between 20 and 99 people", "between 100 and 499 people", "between 500 and 999 people" and "over 1000 people"). Decision-making was a dummy variable coded "1" when non-IT senior executives were involved in the decision and " 0 " otherwise. IT intensive sector was a dummy variable coded " 1 " for the banking, financial services and insurance sectors as well as the electronics and aerospace sectors and " 0 " for other sectors. Institutional environment was a dummy variable coded "1" for Germany and “0” for France.

\section{ANALYSIS AND RESULTS}

We tested our hypotheses using a binomial logistic regression model. For firms that outsourced all or part of their IT, the model estimated the influences of the independent variables on the likelihood of making a total IT outsourcing decision. The logistic regression model took the following form:

Probability of choosing total IT outsourcing over selective IT outsourcing $=1 /\left\{1+\exp ^{(-Y)}\right\}$ where $Y=\beta_{0}+\beta_{1} X_{1}+\beta_{2} X_{2}+\ldots+\beta_{\mathrm{p}} X_{\mathrm{p}}+\varepsilon$

In this equation, $X_{1}, X_{2}, \ldots, X_{\mathrm{p}}$ were the explanatory variables, $\beta_{1}, \beta_{2}, \ldots, \beta_{\mathrm{p}}$ were the corresponding coefficients, $\beta_{0}$ was the intercept term and $\varepsilon$ was the error term.

Table 2 below reports the means, standard deviations, and correlations among the variables. The proportion of total outsourcing cases in the sample is $36 \%$. This figure is significantly higher than the $20 \%$ reported in the United States by Lacity and Willcocks (19). 
Table 2: Means, standard deviations, and correlations among variables $(N=72)$

\begin{tabular}{lcccccccc}
\hline & Mean & S.D. & $\mathbf{1}$ & $\mathbf{2}$ & $\mathbf{3}$ & $\mathbf{4}$ & $\mathbf{5}$ & $\mathbf{6}$ \\
\hline 1. Total IT outsourcing & 0.36 & 0.48 & & & & & & \\
2. Cost motivation & -0.02 & 1.04 & $0.41^{* * *}$ & & & & & \\
3. Performance motivation & 0.02 & 1.03 & -0.19 & -0.19 & & & & \\
4. IT department size & 2.44 & 1.02 & $-0.24^{* *}$ & -0.09 & 0.04 & & & \\
5. Non-IT senior management & 0.47 & 0.50 & 0.10 & $0.23^{*}$ & -0.12 & $-0.22^{*}$ & & \\
decision-making & & & & & & & & \\
6. Sector IT-intensity & 0.29 & 0.46 & $-0.23^{*}$ & $-0.21^{*}$ & -0.03 & 0.05 & -0.56 & \\
7. Institutional environment & 1.60 & 0.49 & -0.15 & 0.17 & 0.07 & -0.01 & $0.21^{*}$ & -0.09 \\
\hline
\end{tabular}

$* \mathrm{p}<0.10, * * \mathrm{p}<0.05, * * * \mathrm{p}<0.01$

Table 3 reports the results of the logistic regression estimations. The overall efficacy of the model was assessed using the likelihood ratio $\chi^{2}$, which is twice the difference in $\log$ likelihood for the current model and the intercept-only model. The model was statistically significant $\left(\chi^{2}=26.09 ; p<0.001\right)$, which suggests that the variables discriminate well between total and selective IT outsourcing. The correct classification rate was $77.80 \%$, which is higher than would be expected by the proportional chance criterion and suggests a good predictive ability. 
Table 3: Results from the logistic regression

\begin{tabular}{lc}
\hline Variables & \\
\hline Constant & $3.54 * *$ \\
Cost motivation & $1.16^{* * *}$ \\
Performance motivation & -0.33 \\
IT department size & $-0.74 * *$ \\
Non-IT senior management & 0.05 \\
decision-making & \\
Sector IT-intensity & $-1.25 *$ \\
Institutional environment & $-1.40 * *$ \\
\hline $\mathrm{N}$ & 72 \\
Model $\chi^{2}$ & 26.09 \\
-2 log likelihood & 68.09 \\
Cases correctly classified & $77.80 \%$ \\
\hline$* \mathrm{p}<0.10, * * \mathrm{p}<0.05, * * * \mathrm{p}<0.01$ &
\end{tabular}

Logistic regression coefficients are reported. Standard errors are in parentheses.

Out of the six hypotheses proposed in section 3, four hypotheses were supported. Hypothesis 1 was strongly supported. Cost motivations were positively and significantly associated with total IT outsourcing $(\beta=1.16 ; p<0.01)$. On the other hand, Hypothesis 2 was not supported. Performance motivations were not significantly associated with total IT outsourcing. Though the sign of the logistic regression coefficient was in the expected negative direction, it was not significant $(\beta=-0.33 ; p>0.10)$. Consistent with hypothesis 3 , the size of the IT department was negatively and significantly related to total IT outsourcing $(\beta=-0.74 ; p<0.05)$. Thus, large IT can more easily resist total IT outsourcing than smaller ones. Hypothesis 4 was not supported. Decisions involving non-IT senior executives did not necessarily lead to total IT outsourcing $(\beta=0.05 ; p>0.10)$. Hypothesis 5 predicted that firms from IT-intensive sectors should be less frequently resort to total IT outsourcing than firms from other sectors. This hypothesis was only moderately supported. Indeed, the significance 
level took the value of 0.07 , which is slightly higher than the customary 0.05 level. Finally, hypothesis 6 stated that total IT outsourcing should be less frequent in Germany than in France. As shown in Table 3, this hypothesis was supported $(\beta=-1.40 ; p<0.05)$.

\section{DISCUSSION}

Findings regarding IT outsourcing motivations were mixed. On the one hand, cost motivations were strongly related to total IT outsourcing. Hence, a convincing possibility of gaining access to cost savings can lead firms to outsource their entire IT department despite the risk of losing control over an important management function. The perspective of an immediate cash infusion may be an especially important driver of such total IT outsourcing decisions. However, the long-term perspective should also be carefully analyzed, as many vendors will buy IT assets to show their goodwill more than for the actual worth of these assets. In the long run, these vendors have to recoup their initial investments and total IT outsourcing efforts may become unprofitable.

Performance motivations were neither negatively nor significantly related to total IT outsourcing. Our basic argument was that vendors cannot be proficient at every IT activity. While a "best of breed" outsourcing strategy may be the best way to improve IT performance, firms that have a low IT performance may also decide to outsource their entire IT department to get rid of IT. This "quick fix approach" may look attractive but it is very likely to have a strong negative impact on IT performance in the long run (43).

The negative and significant link between the IT department size and total outsourcing confirms that it is easier for large IT departments to justify internal operations and resist dismantlement. This can be attributed to their superior scale and expertise but also to their superior power. It has been frequently reported that large companies outsource an increasingly 
broad range of IT activities (e.g., 15). However, our findings show that firms with small IT departments remain far more likely to outsource their entire IT department.

Regarding decision-making, we did not find support for the prediction that non-IT senior management involvement leads to more total IT outsourcing. This is a important indication that non-IT senior management does not necessarily see outsourcing as a way to get rid of the IT department. To summarize, total IT outsourcing does not seem to be more valued by nonIT managers than by IT managers.

The prediction that firms from highly IT intensive industries should be less likely to outsource their entire IT department received moderate support. For firms that belong to IT intensive industries, IT is frequently a "core competence" (14). Selective IT outsourcing may be safely used to access expertise that is not available in-house even when IT is a "core competence". On the other hand, total IT outsourcing involves a loss of control over the entire IT activity. This is something that firms cannot afford when IT is a "core competence" (34 and 38).

Finally, we found support for the impact of the institutional environment on IT outsourcing decisions. In other words, the apparently universal character of IT outsourcing practices should not disguise the fact that national environments may influence them. The comparison between France and Germany is particularly interesting because of the important differences in management practices between the two countries (e.g., 37, 42). While the impact of institutional differences on governance structures had been frequently studied in the case of Japan and the United States (e.g., 3,4), there is far less work comparing French and German institutional environments (see 27 for an exception). In the case of IT outsourcing, our empirical results clearly confirm that German managers are less sensitive than French ones to management fashions such as total IT outsourcing (i.e., «organizational shamelessness »). 


\section{CONCLUSION}

IT outsourcing is often considered as a panacea. For instance, it has been reported to provide immediate access to state-of-the-art technology. Since vendors pool demand from different clients, it has also been associated with lower costs. Finally, it may help firms focus on their "core business" by freeing up financial and managerial resources (34).

However, IT outsourcing is also fraught with hazards. Some of the most important IT outsourcing risks are loss of control and opportunistic expropriation by the vendor $(2,19)$. Opportunistic expropriation occurs when the vendor standardizes IT to the extent that it becomes a commodity. In that case, the unique needs of the client can no longer be longer met. Losing control over IT is all the more dangerous as IT can help create and sustain a competitive advantage by leveraging complementary resources (11). Some activities have simple technical interfaces with the rest of the organization's systems. They can easily be isolated and contracted out. On the other hand, activities such as IT are highly integrated within the firm. As they have complex and extensive interactions with a large number of other parts of the firm, they are far more difficult to outsource.

The risks of total IT outsourcing are also multi-faceted. Firstly, total outsourcing deals are often based on long term contracts. Such contracts are hard to handle when technology and business conditions are uncertain. Secondly, total outsourcing often involves a single vendor while practices such as dual sourcing make the client less vulnerable to the potential opportunism of vendors. Thirdly, only certain types of IT activities may be safely outsourced. For instance, a study reported that the perceived success rate of IT outsourcing was quite high for systems operations and telecommunications outsourcing but far lower for applications development, end user support and systems management outsourcing (15). 
While several empirical studies have investigated the determinants of IT outsourcing (e.g., 2, 26, 39), there has been little research on the reasons why some firms outsource their entire IT activity. In this paper, we have investigated this topic in France and Germany. Though the results may not necessarily extend to other countries, they suggest that total IT outsourcing is more frequent when there are strong cost motivations and when the IT department is small. On the other hand, total IT outsourcing is less frequent in IT intensive sectors and in Germany (compared to France).

Though we strongly believe that the paper sheds new light on an important IT outsourcing issue, it also has several limitations. Firstly, we focused on the total vs. selective outsourcing alternative. While our data cannot extend to these issues, it would be interesting to use the same variables to analyze the IT outsourcing decision, and if so, the total vs. selective IT outsourcing decision. Secondly, our sample size was quite limited because only $45 \%$ of the firms actually outsourced all or part of their IT. Thirdly, our research is crosssectional and it is impossible to figure out whether firms are increasing their current outsourcing level towards total IT outsourcing or decreasing their current outsourcing level towards selective IT outsourcing. Future research with a longitudinal design would be very interesting. A final suggestion is to move beyond the focus on individual effects to examine potential interactions. One potentially fruitful avenue would be to examine how firms deal with tradeoffs among the determinants investigated in this paper. For instance, what should a firm do when the institutional environment encourages selective outsourcing while cost motivations encourage total outsourcing? 


\section{References}

(1) Amit, R. and P. Schoemaker, "Strategic Assets and Organizational Rent", Strategic Management Journal, 14, 1993, pp. 33-46.

(2) Ang, S. and L. Cummings, "Strategic Response to Institutional Influences on Information Systems Outsourcing", Organization Science, 8, 1997, pp. 235-255.

(3) Aoki, M., "Towards an Economic Model of the Japanese Firm", Journal of Economic Literature, 28, 1990, pp. 1-27.

(4) Aoki, M. (1988), Information, Incentives and Bargaining in the Japanese Economy, Cambridge: Cambridge University Press

(5) Arnett, K. and M. Jones, "Firms That Choose Outsourcing: A Profile", Information \& Management, 26, 1994, pp. 179-188.

(6) Barney, J., "Firm Resources and Sustained Competitive Advantage", Journal of Management, 17, 1991, pp. 99-120.

(7) Barthelemy, J., "The Hidden Costs of IT Outsourcing", MIT Sloan Management Review, Spring, 2001, pp. 60-69.

(8) Barron, T., "Some New Results in Testing for Economies of Scale in Computing", Decision Support Systems, 8, 1992, pp. 405-429.

(9) Benamati, J. and T. Rajkumar, "The Application Development Outsourcing Decision: An Application of the Technology Acceptance Model", Journal of Computer Information Systems, 42, Summer 2002, pp. 35-43

(10) Clark, T., R. Zmud and G. Mccray, "The Outsourcing of Information Services : Transforming the Nature of Business in the Information Industry", In Willcocks, L. and M. Lacity (Ed.), Strategic Sourcing of Information Systems: Perspectives and Practices, Chichester: John Wiley, 1998: pp. 103-136.

(11) Clemons, E. and M. Row, "Sustaining IT Advantage: The Role of Structural Differences", MIS Quarterly, 15, pp. 272-292.

(12) Cross, J., "IT Outsourcing: British Petroleum's Competitive Approach", Harvard Business Review, May-June, 1995, pp. 94-102.

(13) Dimaggio, P. and W. Powell, "The Iron Cage Revisited: Institutional Isomorphism and Collective Rationality in Organizational Fields », American Sociological Review, 48, 1983, pp. 147-160.

(14) Grant, R., "The Resource-Based theory of Competitive Advantage: Implications for Strategy Formulation”, California Management Review, 33, 3, 1991, pp. 114-135.

(15) Grover , V., M. Cheon and J. Teng, J., "The Effect of Service Quality and Partnership on the Outsourcing of Information Systems Functions", Journal of Management Information Systems, 12, 4 , 1996, pp. 89-116.

(16) Kahai, P., C. Snyder and H. Carr, "Decentralizing the IS Function: Resources and Locus of Decisions", Journal of Computer Information Systems, 42, Winter 2001-2002, pp. 44-50.

(17) Kim, S. and Y.S. Chung, "Critical Factors for IS Outourcing Implementation from an Interorganizational Relationship Perspective", Journal of Computer Information Systems, 43, Summer, 2003, pp. 81-90.

(18) Lacity, M. and R. Hirschheim, Information Systems Outsourcing, Chichester: John Wiley and Sons, 1993

(19) Lacity, M. and L. Willcocks, "An Empirical Investigation of Information Technology Sourcing Practices: Lessons From Experience”, MIS Quarterly, 22, 1998, pp. 363-408.

(20) Lacity, M., L. Willcocks and D. Feeny, "IT Outsourcing: Maximize Flexibility and Control", Harvard Business Review, May-June 1995, pp. 84-93

(21) Lacity, M., L. Willcocks and D. Feeny, "The Value of Selective IT Outsourcing”, Sloan 
Management Review, Spring 1996, pp. 13-25.

(22) Lawrence, P., Managers and Management In West Germany, London: Croom Helm, 1980.

(23) Lee, J.-N., "The Impact of Knowledge Sharing, Organizational Capability and Partnership Quality on IS Outsourcing Success”, Information \& Management, 38, 2001, pp. 323-335.

(24) Lee, Y. and J.-N. Kim, "Effect of Partnership Quality on IS Outsourcing: Conceptual Framework and Empirical Validation", Journal of Management Information Systems, $15,4,1999$, pp. 29-52

(25) Loh, L. and N. Venkatraman, "Diffusion of Information Technology Outsourcing: Influence Sources and the Kodak Effect", Information Systems Research, 3, 4, 1992, pp. 334-358.

(26) Loh, L. and N. Venkatraman, "Determinants of Information Technology Outsourcing: A Cross-Sectional Analysis", Journal of Management Information Systems, 9, 1, 1992, pp. 7-24.

(27) Maurice, M, F. Sellier and J.-J. Silvestre, Politique d'éducation et organisation industrielle en France et en Allemagne. Essai d'analyse sociétale, Paris: Presses Universitaires de France, 1982.

(28) North, D., Structure and Change In Economic History, New York: W. W. Norton and Co, 1981.

(29) North, D., Institutions, Institutional Change and Economic Performance, Cambridge: Cambridge University Press, 1990.

(30) Pohl, H., "On the History of Organizations and Management In Large German Enterprises Since the $19^{\text {th }}$ Century", In B. Supple (Ed.), the Rise of Big Business, Aldershot: Edward Elgar, 1992.

(31) Poppo, L. and T. Zenger, "Testing Alternative theories of the Firm: Transaction Cost, Knowledge-Based and Measurement Explanations for Make-Or-Buy In Information Services », Strategic Management Journal, 19, 1998, pp. 853-877.

(32) Porter, M. and V. Millar, "How Information Gives You Competitive Advantage", Harvard Business Review, July-August, 1985, pp. 149-160.

(33) Prahalad, C.K. and G. Hamel, "The Core Competence of the Corporation", Harvard Business Review, May-June 1990, pp. 79-91.

(34) Quinn, J. and F. Hilmer, "Strategic outsourcing", Sloan Management Review, Summer 1994, pp. 43-55.

(35) Rogers, E., Diffusion of Innovations ( $4^{\text {th }}$ Edition), New York: Free Press, 1995.

(36) Sambamurphy, V. and R. Zmud, "Arrangements for Information Technology Governance: A Theory of Multiple Contingencies”, MIS Quarterly, 23, 1999, pp. 261290.

(37) Sorge, A., "Management In France"; In D. Hickson (Ed.), Management In Western Europe: Society, Culture and Organization In Twelve Nations, Berlin: Walter De Gruyter, 1993, pp. 65-87.

(38) Teece, D., G. Pisano and A. Shuen, "Dynamic Capabilities and Strategic Management", Strategic Management Journal, 18, 1997, pp. 509-533.

(39) Teng, J., M. J. Cheon and V. Grover, "Decisions to Outsource Systems Functions: Testing A Strategy-theoretic Discrepancy Model”, Decision Science, 26, 1995, pp. 75-103.

(40) Van de Ven, A. and D. Ferry, Measuring and Assessing Organizations, New York: John Wiley and Sons, 1980.

(41) Venkatraman, N., "Beyond Outsourcing: Managing IT Resources as a Value Center “, Sloan Management Review, Spring 1997, pp. 51-64.

(42) Warner, M. and A. Campbell, "German Management", In D. Hickson (Ed.), 
Management In Western Europe: Society, Culture and Organization In Twelve Nations, Berlin: Walter De Gruyter, 1993, pp. 89-108.

(43) Willcocks, L., G. Fitzgerald G. and D. Feeny, "Outsourcing IT: The Strategic Implications", Long Range Planning, 28, 5, 1995, pp. 59-70.

(44) Williamson, O. E., The Economic Institutions of Capitalism, New York: Free Press, 1995.

(45) Yao, J., X. Xiaohe, L. Chang and J. Lu, "Organizational Size: A Significant Predictor of IT Innovation Adoption”, Journal of Computer Information Systems, 43, Winter 20022003, pp. 76-82. 